\title{
SANITATION IN ASYLUMS FOR THE INSANE WITH ESPECIAL REFERENCE TO TUBERCULOSIS.
}

By G. A. MacCALluM, M. D.

Superintendent, Asylum for the Insane, London, Ont.

It is of course to be assumed by the thinking people of a community that if with the aim of caring for or curing those members of their families who are afflicted with mental diseases they assemble them together in a special institution, the patients should at least have nothing to fear from any danger due to lack of the ordinary sanitary precautions. Most of these sanitary precautions are such as lie clearly before the eyes of the officials appointed to the control of asylums and form a part of the every day administrative duties of those officials, but for the combating of certain of the more insidious dangers a detailed medical knowledge is indispensable. I refer of course to the various diseases which may be contracted by one individual from another and which gain a great importance from the mere fact that in such institutions a large number of people are closely housed together and under conditions especially favorable for the spread of disease.

It is remarkable to note how our administrative methods in hospitals and institutions, in combating the extension of epidemics, have been radically altered by the acquisition of precise knowledge of ætiological factors. Even when we do not know the cause in any given case, we can often successfully contend with it by basing our plan of campaign on its analogies with the better known disorders. But, on the other hand, when the advance of bacteriological knowledge has laid before us the actual living cause, has told us all of its life history and its methods of attack, has shown us its weak points and how to take advantage of them to its annihilation-then we can face the enemy with eyes open and with rational tactics. Consider, for example, our present position with regard to diphtheria as 
[Oct.

compared with that of ten years ago. The horrors of an outbreak of diphtheria in a children's hospital are almost completely eliminated from the fact that with the first signs we can inoculate with preventive serum all the children exposed and practically cut short the disease at its onset. How different were the results of the efforts at stamping out the plague in the recent Glasgow epidemic from those in previous centuries in England. Even when we cannot actually put our finger on the living germ which causes the disease, we often know enough about it to take advantage of its characteristics and bring about its destruction.

It will be obvious to every one that no matter what the nature of the poison that produces disease in one person, since our aim is to protect others, it is of paramount importance to us to know (I) how the poison gets out of the body of such a sick person; (2) how it is carried from one person to another; and (3) how it gains entrance into the body of the second person. It is equally obvious that if we know these things we can apply rational methods to interfere with the progress of the poison at any one of these three periods and it is with these essential points that we are particularly concerned in sanitation.

It would be far beyond the scope of a brief paper to discuss these subjects with reference to diseases in general, but of their bearing upon one disease, which seems of especial importance to those in charge of asylums, we may speak in some detail.

Before the discovery of the tubercle bacillus great obscurity prevailed as to the real nature of pulmonary consumption. It was in a general way known to be a disease which could probably be communicated to animals and was thought to be in some degree a menace to surrounding persons. With the first sight of the bacillus, however, it became clear that the mechanism of its transmission was a very effective one and that the menace was very real and serious. Whether the import of this discovery was overrated or underestimated remains to be seen.

If we consider tuberculosis in relation to the three important points referred to above we gain a very clear light on the mode of transmission.

First, as to the mode of excretion of the living bacillus from the body of a diseased person, it is plain that this will depend 
on the position of the morbid foci. Thus in tuberculous disease situated in the intestinal tract myriads of tubercle bacilli are discharged with the fæces, while in tuberculosis of the genito-urinary tract great numbers are discharged in the urine. Any ordinary sanitary precautions such as are in force in every asylum are, however, sufficient to obviate any danger from these sources. Tuberculosis of various other organs, bones, joints, meninges, etc., where there is no direct communication with the external world, is not followed by a distribution of the bacilli and is not at all dangerous, per se, to surrounding persons. But finally, in by far the greater proportion of all cases of tuberculosis there is disease of the respiratory organs and in this lies the danger to others. I need not dwell on the changes which take place in the lungs-suffice it to say that there is a breaking down of lung tissue into a semi-fluid material containing the bacilli in countless myriads, which is constantly being coughed up and expectorated. The enormous importance of this direct discharge of virulent tubercle bacilli must be plain to all. The very fact that coughing is with these patients such a constant occurrence, that they cough in the presence of other people and that too often they are not careful to dispose of the infected material, but spit it about on the floor or ground, shows that the chances of its dissemination are great indeed.

It has always been plain, since we have learned to appreciate the infectious nature of such sputum, that it bore with it a direct menace to surrounding persons. Just how the infectious agent was transmitted, however, had not been quite so clear until recently, after numerous experiments had been instituted to investigate the fate of such expectoration. It has been found that the tubercle bacillus can readily withstand complete drying and when transplanted in this dry state into the body of another person will quickly reawaken and grow, multiply and produce tuberculosis. We can, therefore, appreciate the readiness with which sputum dried on the floor, bedclothing, handkerchiefs, etc., could be diffused into the air and breathed in by some bystander to the production of tuberculosis in his lungs. It has been found that the tubercle bacilli will actually float about in the air if they are dry enough and mixed with dust in a sufficiently fine state of division. Such dust has been experimented 
with. Handkerchiefs used by consumptives have been dried and shaken in the air of cages in which guinea-pigs, which are so susceptible to the disease, were kept and the animals have frequently contracted tuberculosis. The percentage of infections has indeed been large and the results leave no doubt as to the great importance of this factor. The sputum, however, must be very thoroughly dried before it can be incorporated with the dust. A very little moisture will suffice to keep the material in such large clumps that it will not float in the air. The handkerchiefs of patients are seldom allowed to dry so completely in practice, but carelessness with regard to floors and furniture and bedding, which results in the complete drying of tuberculnus material, must be very common. The scraping of feet over such dried sputum must stir up clouds of infectious dust, although it settles quite rapidly, and the shaking of soiled bedding and clothing must be equally productive of a haze of tubercle bacilli. The dread significance of this is only too evident.

Even more important however, because more insidious, is another method of distribution of the bacilli. Most careful experiments have shown that with every spoken word of an advanced consumptive, with every cough or sneeze, there is exhaled a mist of the finest fluid droplets, which float in the air and carry with them virulent tubercle bacilli. When glass slides have been placed before such people, at a distance of a yard, and stained after a short period of talking and coughing, tubercle bacilli have been demonstrated adhering to them. Again, after such patients have been caused to cough and talk into a large box in which guinea-pigs were kept, many of the animals have contracted tuberculosis. Twenty-five guinea-pigs were taken and placed on a table before tuberculous patients or held in their hands while they coughed toward them-of these six contracted tuberculosis and died. ${ }^{2}$

What a new light these studies seem to throw upon the relations which should be maintained between tuberculous patients and others. No amount of care in the disinfection of sputum will obviate the danger of infection from the cloud of floating

' Flügge. Ztschr. für Hygiene, I898, XXX. 
moist bacilli. It is true that if the handkerchief be held closely before the mouth in coughing, the patients may avoid, in part at least, the wide distribution of the cloud; but what can such efforts avail during the weeks or even years through which the disease drags its course? It is true, too, that if one only occasionally approaches such a patient or consistently keeps a distance of over one or two yards the danger is much less, but how can such rules be applied to patients closely housed together as they are in asylums.

Evidently, then, a tuberculous patient is a source of constant danger to those living about him, not only from the fact that any carelessness with his sputum leads to its dissemination, its drying on floors, furniture, etc., and its final pulverization after which it is readily stirred up into the air and breathed into the lungs of other patients, but also from the fact that he constantly exhales an invisible poisonous cloud or mist of finest fluid droplets often laden with tubercle bacilli and easily breathed into the lungs of a healthy person.

All of these risks-sufficiently difficult to combat by hygienic regulations among intelligent sane individuals-become entirely impossible when one is dealing with insane patients crowded together in great numbers.

These conditions explain very well the various modes of occurrence of tuberculosis. Its frequency in crowded tenements, and especially its incidence in groups in one house, the occurrence of abundant cases in old institutions-all point to a transmission from individual to individual. Of course race susceptibility plays an important part, and certain individuals seem from birth inclined to infection with tuberculosis. In other cases, however, the conditions found in a hospital for the insane are of paramount importance, namely, the more or less lowered resistance produced by the disturbances, for the relief of which they primarily enter the institution, and the intimate contact with other patients, some of whom may be sources of tuberculous infection.

One is shocked on entering one of our provincial asylums with these thoughts, to find that with complete disregard of all possible precaution patients far advanced in tuberculosis are sometimes huddled together in crowded wards with other cases. 
They are irresponsible and careless, they spit on the floors, drivel on their clothes, use the same forks and spoons with all the rest and thus spread the germs of disease among the other patients. Not only this, they actually taint the air with their poisonous breath, their constant cough drives the bacilli in the air into the faces of their fellow patients, with a pertinacity which, lasting weeks and months, can hardly fail to lead to the infection of patients who might perhaps with impunity approach such consumptives for a short time only.

With our eyes opened to this danger, is it not reprehensible neglect to allow such a state of affairs to continue? Are we not betraying a trust in taking charge of these people, only to expose them to a disease almost as horrible as that for which they have sought our help?

What measures then, we may ask, can be adopted to better the situation? Personal hygiene is of course important-if it were possible with carefully attended spittoons and carefully enforced regulations to nullify all the sputum containing tubercle bacilli, this would be a great step in advance. With insane patients, however, in institutions accommodating many hundreds, it is safe to say that this cannot be done. The control of the second mode of dissemination, the spraying of tuberculous sputum, is even more absolutely impossible under such conditions. The only remedy which can be at all effective is the isolation of the patients, the method which we apply with such rigor to other no more infectious diseases, diseases which are not nearly so extensively fatal, but which we fear because their onset is violent and sudden. Without a doubt isolation is imperative here. This fact is recognized everywhere and sanatoria for tuberculous patients are being erected in many places in this country and have been established for many years in older countries.

Their aim is also isolation of the patient for his own sake. In the case in point this consideration, as well as the welfare of the other patients, is of the greatest importance. There is not a doubt that patients in the early stages of consumption are benefited by the enlargement of their surroundings, the better general hygienic conditions which can be obtained in the more isolated mode of life and especially by an abundant and con- 
stant supply of fresh air. The work done by Trudeau abundantly exemplifies this, in the results obtained by the treatment of tuberculous patients in the cottage sanatorium in the Adirondacks.

The remedy for this evil in the asylum seems, therefore, simple enough. There should be built upon a sunny part of the grounds-as distant as possible from the other wards-cottages for the isolation of the tuberculous patients. Each should be large enough to accommodate only a few patients, or if it be possible to build only one for male and one for female patients, they should be so arranged to give the best possible ventilation and exposure to sunlight. Verandas should be provided for the exposure of bedridden patients to the open air and the special attendants should be instructed in the carrying out of the measures of personal hygiene suggested above. The imperative necessity for such means of isolation must be plain to all. The seriousness of the white plague of tuberculosis is so often underestimated, on account of its slow and insidious onset and course, that the most dreadful ravages are permitted when by intelligent sanitation we might at least do much to diminish it. 